\title{
Rotordynamics of Turbine Labyrinth Seals with Rotor Axial Shifting
}

\author{
Jinxiang Xi and David L. Rhode \\ Department of Mechanical Engineering, Texas A\&M University, College Station, TX 77843, USA
}

Received 18 September 2005; Accepted 29 December 2005

\begin{abstract}
Rotors in high-performance steam turbines experience a significant axial shifting during starting and stopping processes due to thermal expansion, for example. This axial shifting could significantly alter the flow pattern and the flow-induced rotordynamic forces in labyrinth seals, which in turn, can considerably affect the rotor-seal system performance. This paper investigates the influence of the rotor axial shifting on leakage rate as well as rotordynamic forces in high-low labyrinth seals over a range of seal clearances and inlet swirl velocities. A well-established CFD-perturbation model was employed to predict the rotordynamic coefficients. A surprisingly large effect was detected for rotordynamic characteristics due to rotor shifting. It was also found that a less destabilizing effect arose from rotor axial shifting in the leakage flow direction, whereas a more destabilizing effect arose from shifting against the leakage flow direction. Further, a tentative explanation was proposed for the large sensitivities of dynamic forces to rotor axial shifting.
\end{abstract}

Copyright (C) 2006 J. Xi and D. L. Rhode. This is an open access article distributed under the Creative Commons Attribution License, which permits unrestricted use, distribution, and reproduction in any medium, provided the original work is properly cited.

\section{INTRODUCTION}

The primary function of labyrinth seals is to either minimize or control leakage, while a secondary but equally important purpose is to provide (or at least not to deteriorate) rotordynamic stability. The fluid within the seals generates reaction forces acting on the rotor. For small rotor displacements about the center position, the reaction forces $F_{x}$ and $F_{y}$ can be modeled as a linearized set of equations:

$$
\begin{aligned}
-\left[\begin{array}{l}
F_{x} \\
F_{y}
\end{array}\right]= & {\left[\begin{array}{cc}
K & k \\
-k & K
\end{array}\right]\left[\begin{array}{l}
x \\
y
\end{array}\right] } \\
& +\left[\begin{array}{cc}
C & c \\
-c & C
\end{array}\right]\left[\begin{array}{l}
x^{\prime} \\
y^{\prime}
\end{array}\right]+\left[\begin{array}{cc}
M & m \\
-m & M
\end{array}\right]\left[\begin{array}{l}
x^{\prime \prime} \\
y^{\prime \prime}
\end{array}\right] .
\end{aligned}
$$

In (1), $x, x^{\prime}, x^{\prime \prime}$ and $y, y^{\prime}, y^{\prime \prime}$ are rotor displacements, velocities, and accelerations in the $x$ and $y$ directions; $K$ and $k$ are the direct and cross-coupled stiffness coefficients; $C$ and $c$ are the direct and cross-coupled damping coefficients; and $M$ and $m$ are the direct and cross-coupled inertial coefficients, respectively. Among the above force coefficients, the tangential components $k$ and $C$ are important in determining rotordynamic stability. The combined effect of these two coefficients forms the effective damping $C_{\text {eff }}[=C-k / \Omega]$.
The reaction forces of labyrinth seals were studied experimentally in the past two decades by Iwatsubo [1], Scharrer and Childs [2,3], Soto and Childs [4], and Kwanka and Nagel [5]. Numerical efforts to predict the reaction force date back to 1965 when Alford reported the initial analysis for labyrinth seals. Bulk flow models were proposed and refined by Black and Jensen [6] and Childs [7], among others. The quasithree-dimensional CFD-perturbation model was introduced to improve the accuracy shortcoming of labyrinth bulk flow models and to reduce the large CPU requirement of full 3D CFD models. Dietzen and Nordmann [8] developed the first CFD-perturbation model based on a coordinate transformation approach. However the coordinate transformation is not precise for complicated seal geometries. Kim and Rhode [9] proposed an approach to approximate the boundary conditions on the disturbed rotor surface which avoids the coordinate transformation and is applicable for axisymmetric seals of any geometry. More recently, Xi and Rhode $[10,11]$ developed a new approach that more precisely describes the inlet boundary conditions for labyrinth seal rotordynamics models.

Rotors in large steam turbines experience noticeable thermal axial growth during transient operations such as the start-up process. The rotor axial shifting caused by the thermal expansion could significantly alter the performance 


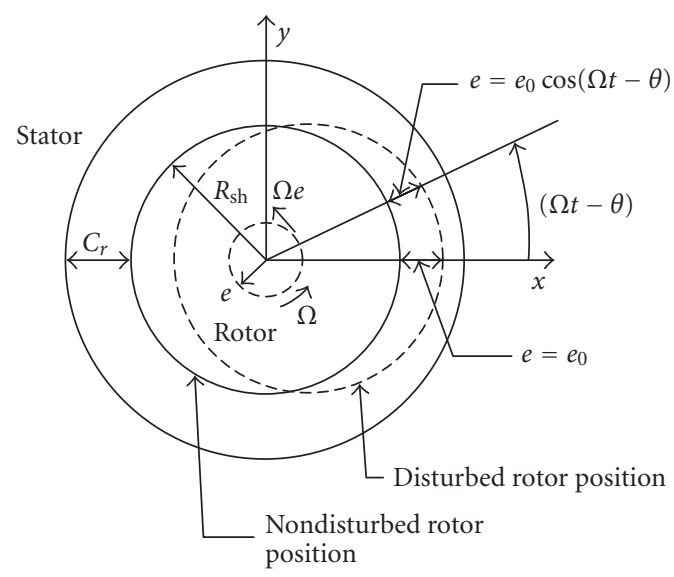

Figure 1: Geomatric and kinematic relationship of circular rotor whirl about the stator center at $t=0, \omega$ : rotating speed; $\Omega$ whirling speed.

and rotordynamic forces of the sealing labyrinth. The seal forces could contribute to the rotordynamic instability of the rotor-bearing-seal system even though the force magnitude is smaller than that of the bearing fluid film forces. As the rotating speed increases or the seal clearance decreases, the labyrinth-seal-excited problems often become more and more critical in the system design. It is therefore necessary to predict these forces accurately for both reliable operations and the future design of high-performance steam turbines.

Despite the exigency of this problem, experimental or numerical data addressing the effect of the rotor axial shifting on the seal rotordynamic characteristics is rare. Baumann [12] investigated the damping behavior for a high-pressure radial compressor and mentioned that axial rotor positions seemed to have insignificant influence on tangential forces and hence could not be verified as the root cause for the system instability. More recently, Wang et al. [13] studied the flow characteristics in stepped seals when teeth disengagements occur due to axial movement and showed that the airflow features are largely dictated by the teeth tip to step distance. The issue of how the rotordynamic forces respond in the presence of rotor shifting for labyrinth seals, however, still remains untouched.

\section{Objectives}

This paper was partially motivated by the lack of reported data on the rotordynamic characteristics under rotor axial shifting circumstances, and was aimed at gaining an insight into the rotordynamics of labyrinth seals under these conditions using the CFD-perturbation modeling method. Specific objectives include the following.

(1) To predict the rotordynamic coefficients in a high-low labyrinth seal with various rotor axial shifting, and over a range of seal clearances and inlet swirl velocities.

(2) To explain the surprisingly large sensitivity variation of dynamic forces to seal configurations due to rotor shifting.

(3) To provide useful information for high-low seal designs.

The CFD-perturbation rotordynamics model employed in this study will be described in Section 2. Its validation against measurements (Soto and Childs [4]) is briefed in Section 3. The predicted influence of rotor axial shifting on both leakage and seal dynamic forces under various operational conditions will then be presented and discussed in Section 4, with a summary following in Section 5.

\section{CFD-PERTURBATION MODEL}

\subsection{Perturbed governing equations}

The flow field in the eccentric seal clearance, as shown in Figure 1, is characterized as unsteady, three-dimensional and turbulent. Thus, the governing equations are the timeaveraged, turbulent Navier-Stokes and continuity equations in a stationary reference frame:

$$
\begin{gathered}
\frac{\partial\left(\rho u_{i}\right)}{\partial t}+\frac{\partial}{\partial x_{j}}\left(\rho u_{i} u_{j}\right)=-\frac{\partial P}{\partial x_{i}}+\frac{\partial \tau_{i j}}{\partial x_{j}} \\
\frac{\partial \rho}{\partial t}+\frac{\partial}{\partial x_{j}}\left(\rho u_{j}\right)=0 .
\end{gathered}
$$

The Reynolds stress is given in cylindrical coordinates as:

$$
\left[\tau_{i j}\right]=\left[\begin{array}{ccc}
2 \mu_{e} \frac{\partial u}{\partial x}-\Pi & \mu_{e}\left(\frac{\partial u}{\partial r}+\frac{\partial v}{\partial x}\right) & \mu_{e}\left(\frac{1}{r} \frac{\partial u}{\partial \theta}+\frac{\partial w}{\partial x}\right) \\
\mu_{e}\left(\frac{\partial u}{\partial r}+\frac{\partial v}{\partial x}\right) & 2 \mu_{e} \frac{\partial v}{\partial r}-\Pi & \mu_{e}\left(r \frac{\partial}{\partial r}\left(\frac{w}{r}\right)+\frac{1}{r} \frac{\partial v}{\partial \theta}\right) \\
\mu_{e}\left(\frac{1}{r} \frac{\partial u}{\partial \theta}+\frac{\partial w}{\partial x}\right) & \mu_{e}\left(r \frac{\partial}{\partial r}\left(\frac{w}{r}\right)+\frac{1}{r} \frac{\partial v}{\partial \theta}\right) & 2 \mu_{e}\left(\frac{1}{r} \frac{\partial w}{\partial \theta}+\frac{v}{r}\right)-\Pi
\end{array}\right],
$$


Assuming high Reynolds number, which has been widely found in turbomachinery seals, the standard form of the $\kappa-\varepsilon$ turbulence model (Launder and Spalding [14]) is used. When the working fluid is compressible, the equation of state is also employed:

$$
P=\gamma \rho R T
$$

where $\gamma$ is the compressibility factor and $R$ is the universal gas constant.

Based on the observation that the rotor boundary motion (i.e., radial clearance) is both temporally and circumferentially periodic, and the assumption that the eccentricity of the rotor is small compared with the seal radial clearance, one can approximately decompose the displaced rotor surface as well as the disturbed flow variables into a steady, axisymmetric part, and a small, unsteady, asymmetric part (see Figure 1) as

$$
\begin{aligned}
& \Phi(x, r, \theta, t) \\
& =\Phi_{0}(x, r)+\varepsilon\left\{\Phi_{1 c}(x, r) \cos (\Omega t-\theta)-\Phi_{1 s}(x, r) \sin (\Omega t-\theta)\right\},
\end{aligned}
$$

where $\Phi$ is a generic flow variable, and $\varepsilon=e / C_{r}$ with $e \ll C_{r}$. Further, $\Phi_{0}$ represents the axisymmetric (zeroth-order, i.e., undisturbed) part, while the first-order $\Phi_{1 C}$ and $\Phi_{1 S}$ are the cosine and sine components of the first-order (i.e., disturbed) part varying only in the $x-r$ space. Equation (4) implies that the rotor small circular whirl motion about the seal housing center generates a periodic flow disturbance. Observe that the first-order quantity $W_{1 C}(x, r)$, for example, represents the cosine swirl velocity disturbance component from rotor eccentricity within the $\theta$-plane at the circumferential position of minimum seal clearance as shown in Figure 1. Similarly, the first-order quantity $W_{1 S}(x, r)$ represents the sine swirl velocity disturbance component within the $\theta$-plane at the circumferential position that is $90^{\circ}$ ahead of the minimum seal clearance. It is assumed that the turbulent viscosity, turbulent kinetic energy and turbulent energy dissipation are not significantly influenced by the whirling rotor motion. Application of (3), (4), and (6) into (2) yields the perturbed zeroth- and first-order equations. The Reynolds-averaged Navier-Stokes equations are first solved to obtain the zeroth-order solution with the rotor in the centered position within the seal housing. Then the firstorder solution of the perturbed Navier-Stokes equations is obtained to account for a very small rotor displacement (i.e., perturbation) from the centered position. Finally, by integrating the circumferential pressure variation around the circumference of the rotor within the seal the flow-induced forces on the rotor are evaluated. Further details are available in [10] and [15]. The same finite volume grid was utilized for zeroth- and first- order computations based on the perturbation of boundary conditions. The SIMPLEC algorithm was used in the present study in combination with the QUICK differencing scheme for the convection terms to minimize the numerical diffusion.

\subsection{Rotordynamic force coefficients}

The reaction forces acting on the whirling rotor can be obtained by integrating the disturbance pressures along the rotor surface as

$$
\begin{gathered}
-\frac{F_{r}}{e}=\left.\pi \int_{L} \frac{\partial P_{o}(x, r)}{\partial r}\right|_{R_{\mathrm{sh}}} R_{\mathrm{sh}} d x+\frac{\pi}{C_{r}} \int_{L} P_{1 c}\left(x, R_{\mathrm{sh}}\right) R_{\mathrm{sh}} d x \\
-\frac{F_{t}}{e}=\frac{\pi}{C_{r}} \int_{L} P_{1 s}\left(x, R_{\mathrm{sh}}\right) R_{\mathrm{sh}} d x .
\end{gathered}
$$

The relations between the radial and tangential forces and the rotordynamic force coefficients are expressed as

$$
-\frac{F_{r}}{e}=K+c \Omega-M \Omega^{2} ; \quad-\frac{F_{t}}{e}=-k+C \Omega+m \Omega^{2} .
$$

By using the above relations and a least square cure fitting in terms of the whirling speed, one can obtain the rotordynamic force coefficients for different flow conditions. Here $k$ and $C$ are important for seal rotordynamic stability and represent cross-coupled stiffness and direct damping, respectively. The effective damping $C_{\text {eff }}(=C-k / \Omega)$ represents the net stabilizing force.

\section{VALIDATION AGAINST MEASUREMENT}

This CFD-perturbation model was validated by comparing it with measurements of a gas labyrinth seal with shunt injection (Soto and Childs [4]). This seal is very long with originally 20 teeth on the stator wall. The fourth tooth from the high-pressure end was removed through which highpressure air was injected against shaft rotation at a $30^{\circ}$ angle from the tangent. Complex flow patterns exist inside the seal due to the presence of many cavities, tight clearances, and high shaft speeds. In addition, this was a highly challenging case because of its high inlet swirl against rotation and high seal exit Mach numbers.

Three whirl-spin ratios (whirl/spin $=0.0,0.25$ and 0.5 ) were computed to obtain each rotordynamic force coefficient. Figure 2 shows the predicted effective damping coefficient at $\omega=4680 \mathrm{rpm}$ and $\omega=8640 \mathrm{rpm}$, both of which give excellent agreement with the measurements (Soto and Childs [4]). More details can be found in [11].

\section{RESULTS AND DISCUSSIONS}

\subsection{CFD considerations}

The schematic diagram of the investigated high-low labyrinth seal is shown in Figure 3(a). It consists of five rotor blocks and a total of eleven teeth, with six long teeth and five short ones alternately arranged. Letters " $\mathrm{A}$ " to " $\mathrm{S}$ " are points located upon the grooved rotor surface. Section "D$\mathrm{E}$ " is the high-portion rotor surface on the first rotor block, while section "F-G" is the low-portion surface immediately downstream from the first block. The axial rotor position relative to the teeth is shown in Figure 3(b). In the present study, the ratio $\mathrm{a} / \mathrm{b}$ varied in a range of $0 \sim 1.0$ as the rotor 


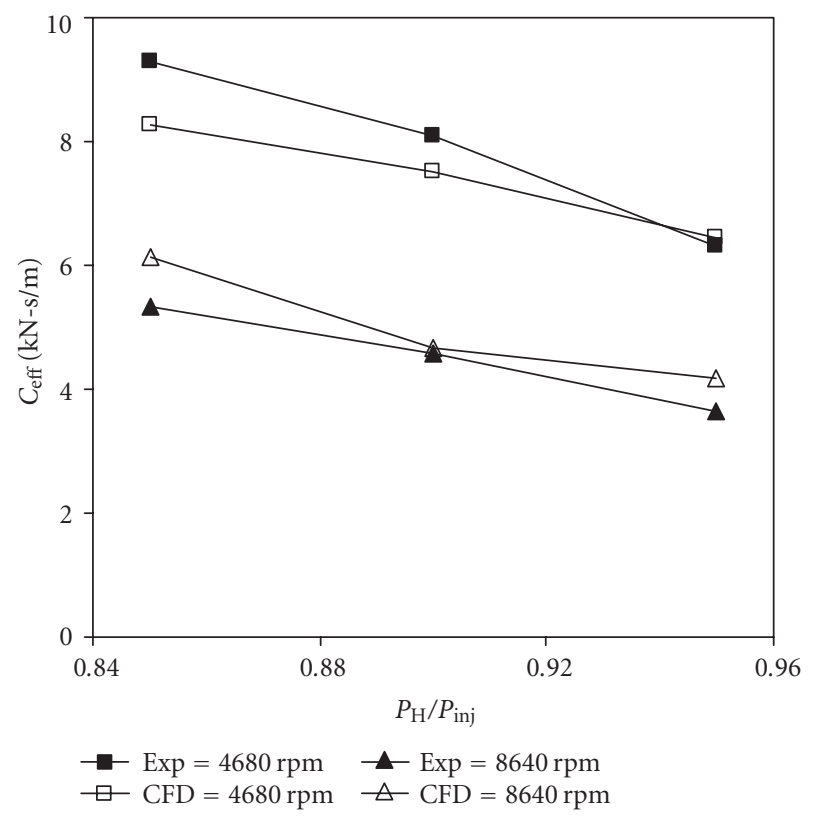

FIGURE 2: Validation of the perturbation model against measurements of (Soto and Childs [4]) effective damping coefficient at pressure ratio $P R\left(=P_{L} / P_{H}\right)=0.65$ and $\omega=4680 \mathrm{rpm}, 8640 \mathrm{rpm}$, respectively.

experienced axial shifting relative to the stator. When $\mathrm{a} / \mathrm{b}=$ 0.5 , the shorter teeth are centered upon the rotor blocks, which is the position of design without any rotor displacement; $a / b$ increases from 0.5 when the rotor shifts in the direction of leakage flow (i.e., downstream rotor shifting) and decreases from 0.5 when shifting against the direction of leakage flow (i.e., upstream rotor-shifting). The straightthrough labyrinth seal shown in Figure 3(c) is a variant of the high-low labyrinth seal with the rotor blocks removed but with all the clearances unchanged.

Steam was used as the working fluid, and the running speed was 3,600 rpm. The labyrinth seal geometric details and operating conditions are listed in Table 1. Seal inlet swirl velocity as well as pressures upstream and downstream of the seal were important boundary conditions. On the rotor and stator walls, no-slip surface conditions were specified via standard wall-functions. The near wall computational cells have both $y^{+}$and $x^{+}$within the range from 15 to 90 on both the high-portion and the low-portion surfaces along the seal.

Grid independence testing was performed with an upstream pressure of $30.4 \mathrm{bar}$, a downstream pressure of 19.34 bar, and an inlet swirl velocity of $75 \mathrm{~m} / \mathrm{s}$. Four grids were tested as shown in Table 2. Grid independence was achieved at $656 \times 65$ lines and was used as the production grid.

\subsection{Leakage}

Figure 4 shows the variation of the predicted leakage flow rate with relative axial rotor positions at three seal clearances. It was found that a small leakage variation was induced by ro-

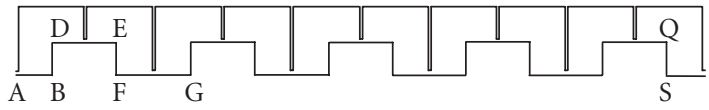

(a)
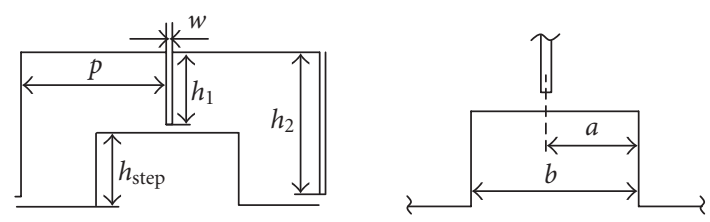

(b)

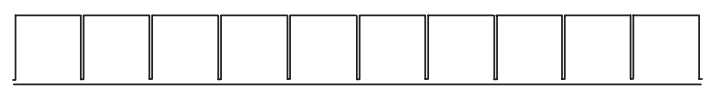

(c)

FIGURE 3: Schematic of labyrinth seals: (a) typical high-low labyrinth seal configuration; (b) seal dimensions and relative tooth axial position $(0.0 \leq \mathrm{a} / \mathrm{b} \leq 1.0)$; (c) straight-through labyrinth seal configuration.

tor shifting. For example, the leakage shows a 9.4\% increase when the rotor shifts against the flow direction from $\mathrm{a} / \mathrm{b}$ $=0.5$ to $\mathrm{a} / \mathrm{b}=0.0$ (i.e., the most upstream position), and only a $4.6 \%$ decrease when the rotor shifts downstream from $\mathrm{a} / \mathrm{b}=0.5$ to $\mathrm{a} / \mathrm{b}=1.0$ (i.e., the most downstream position). Furthermore, for a given seal pressure difference the steam leakage is observed to vary approximately proportionally with the seal radial clearance.

The vector plots of Figure 5 show different flow patterns for a high-low labyrinth seal at three relative axial rotor positions, that is, $\mathrm{a} / \mathrm{b}=0.0,0.5$, and 1.0 . The fluid approaches the long-teeth tip nearly horizontally (see the right-hand side of Figure $5(\mathrm{a})$ ) when $\mathrm{a} / \mathrm{b}=0.0$, although it approaches at a sharp angle when $\mathrm{a} / \mathrm{b}=0.5$ and 1.0. Figure $5(\mathrm{~b})$ shows that two large recirculation zones exist upstream of the shorter teeth for the rotor position $\mathrm{a} / \mathrm{b}=0.5$. The recirculation zone above the rotor block continuously decreases in size as the rotor shifts downstream from the teeth-centered position. An abrupt change in flow pattern of this recirculation zone occurs when $\mathrm{a} / \mathrm{b}$ reaches 1.0 , where the recirculation zone vanishes. It is consistent with the findings from Figure 4 that at large clearances the leakage rate recovers slightly when $\mathrm{a} / \mathrm{b}$ $=1.0$, while the leakage rate decreases continuously as $\mathrm{a} / \mathrm{b}$ increases from 0.0 to 0.75 . It is speculated that this recovery around $\mathrm{a} / \mathrm{b}=1.0$ is related to the disappearance of the small recirculation zone.

Extreme conditions such as when shorter teeth shift off the rotor block (i.e., $\mathrm{a} / \mathrm{b}<0$ or $\mathrm{a} / \mathrm{b}>1.0$ ) were also computed. In these situations, the leakage and the induced dynamic forces behave quite differently and both increase significantly in magnitude. Therefore, the high-low labyrinth seals should be designed to have enough of a safety margin in order to avoid operation in such flow regimes. 
TABLE 1: Dimensions and conditions for typical high-low labyrinth seals in steam turbines.

\begin{tabular}{lccc|ccc|c|cccc}
\hline \multicolumn{8}{c|}{ Dimensions } & \multicolumn{4}{c}{ Conditions } \\
\hline $\begin{array}{l}\text { Stator } \\
(\mathrm{mm})\end{array}$ & $\begin{array}{c}p \\
(\mathrm{~mm})\end{array}$ & $\begin{array}{c}h_{1} \\
(\mathrm{~mm})\end{array}$ & $\begin{array}{c}h_{2} \\
(\mathrm{~mm})\end{array}$ & $\begin{array}{c}b \\
(\mathrm{~mm})\end{array}$ & $\begin{array}{c}h_{\text {step }} \\
(\mathrm{mm})\end{array}$ & $\begin{array}{c}R_{\mathrm{sh}} \\
(\mathrm{mm})\end{array}$ & $\begin{array}{c}C_{r} \\
(\mathrm{~mm})\end{array}$ & $\begin{array}{c}W_{0} \\
(\mathrm{~m} / \mathrm{s})\end{array}$ & $\begin{array}{c}P_{\text {up }} / P_{\mathrm{dn}} \\
(\mathrm{bar})\end{array}$ & $\begin{array}{c}\omega \\
(\mathrm{rpm})\end{array}$ & $\begin{array}{c}T \\
(\mathrm{~K})\end{array}$ \\
\hline 0.254 & 7.366 & 3.175 & 6.350 & 5.334 & 3.175 & 152.4 & $\begin{array}{c}0.254 \\
0.762\end{array}$ & $8 \sim 208$ & $30.34 / 19.72$ & 3,600 & 749 \\
\hline
\end{tabular}

TABLE 2: Grid independence testing results.

\begin{tabular}{ccccc}
\hline \multirow{2}{*}{$N I \times N J$} & $k$ & $\frac{\left(k_{c}-k_{f}\right)}{k_{f}}$ & $C$ & $\frac{\left(C_{c}-C_{f}\right)}{C_{f}}$ \\
& $(\mathrm{MN} / \mathrm{m})$ & $(\%)$ & $(\mathrm{KNs} / \mathrm{m})$ & 2.56 \\
$(\%)$ \\
\hline $546 \times 48$ & 0.555 & - & 2.79 & 8.67 \\
$766 \times 65$ & 0.610 & 8.9 & 2.81 & 0.73 \\
$892 \times 86$ & 0.616 & 1.03 & 2.82 & 0.52 \\
\hline
\end{tabular}

$f$ represents the next finer grid.

$c$ represents the coarse grid.

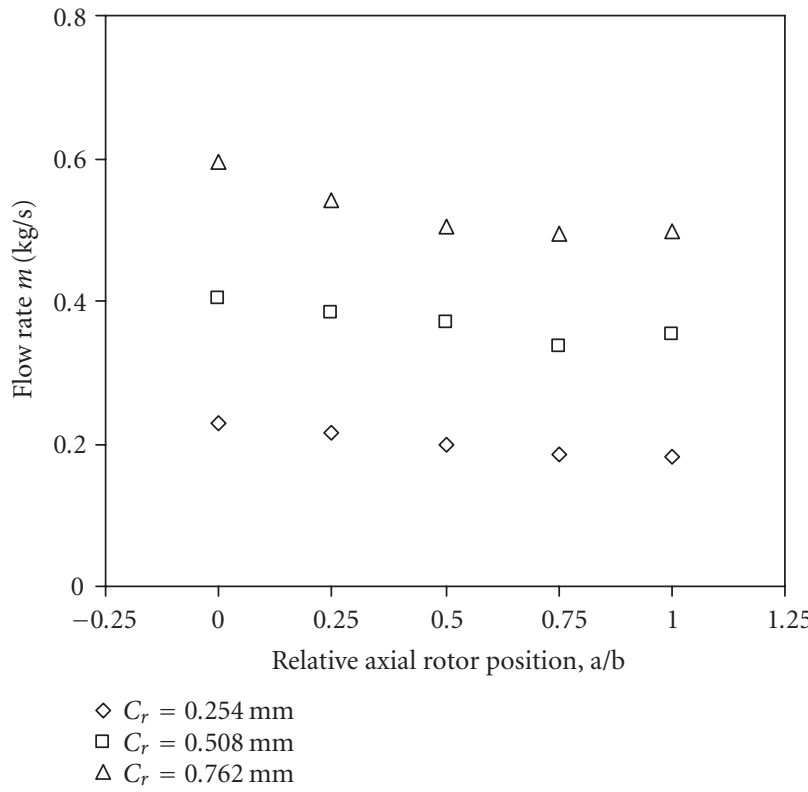

Figure 4: Predicted mass flow rate versus relative axial rotor position $\mathrm{a} / \mathrm{b}$ for high-low seals.

\subsection{Rotordynamic forces}

The seal rotordynamic behavior subject to rotor shifting is important and must be predicted accurately. Various operating conditions were investigated which cover a wide range of seal clearances and inlet swirl velocities as shown in Figures 6 through 10. One important finding from the above figures is that the rotor axial shifting produces a surprisingly large effect on rotordynamic forces, which will be explained in detail below.

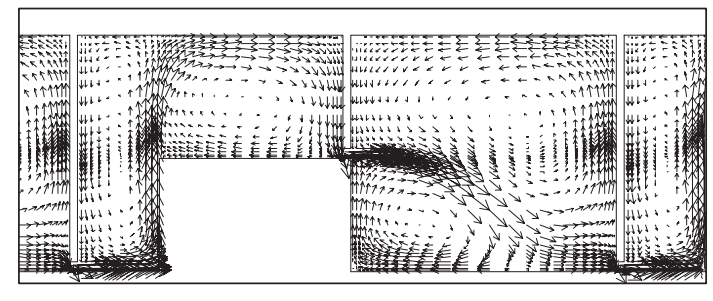

(a)

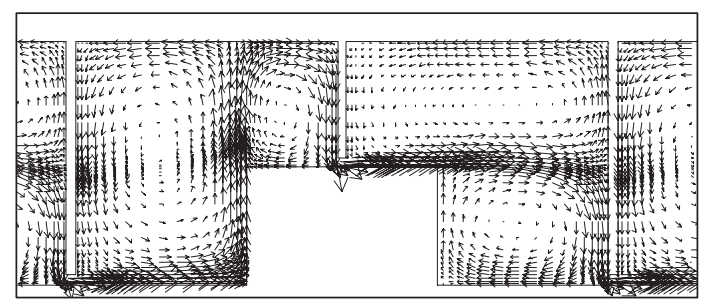

(b)

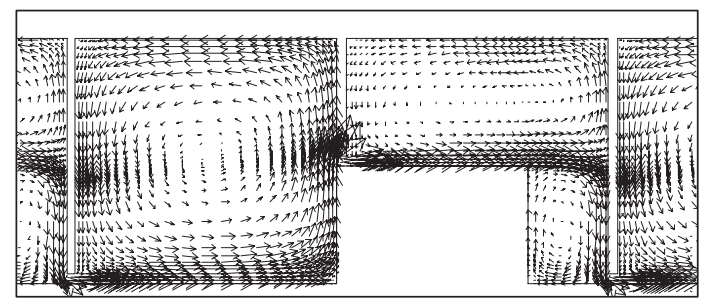

(c)

FIGURE 5: Flow patterns within a high-low seal for different relative axial rotor positions, $C_{r}=0.254 \mathrm{~mm}$ : (a) a/b $=0.0$; (b) a/b $=0.5$; (c) $\mathrm{a} / \mathrm{b}=1.0$. 


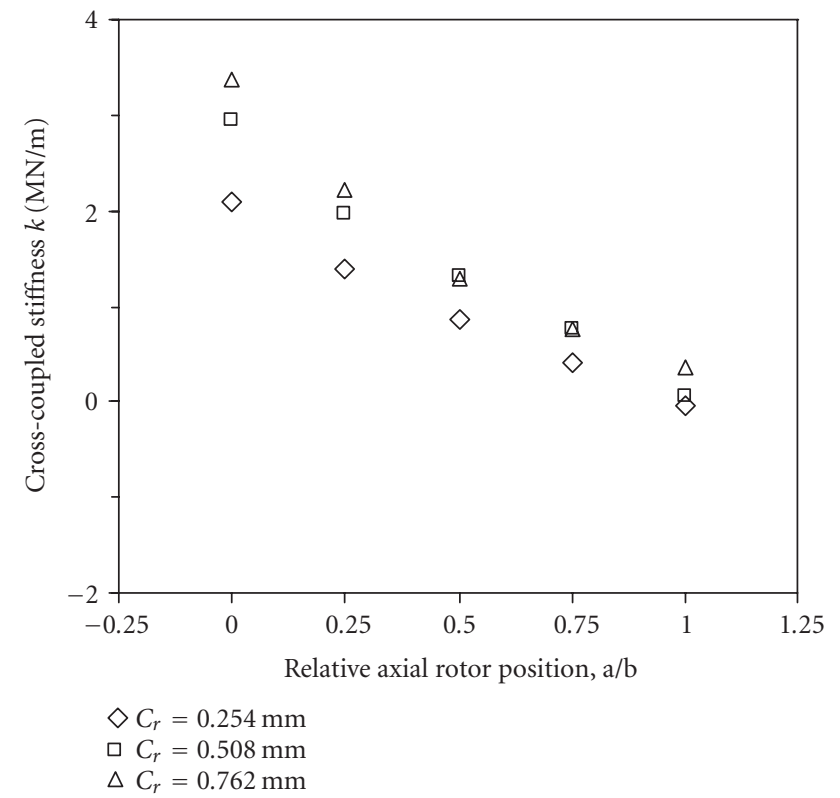

(a)

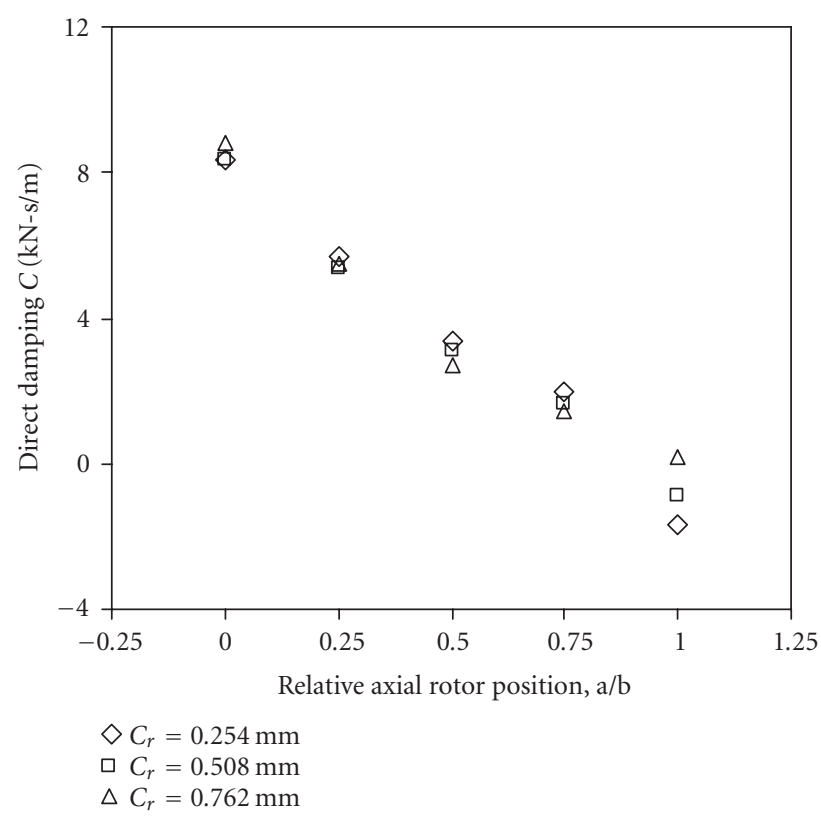

(b)

Figure 6: Predicted tangential force coefficients versus relative axial rotor position a/b for high-low seals: (a) cross-coupled stiffness; (b) direct damping.

Figure 6 shows the variation of the cross-coupled stiffness $k$ and direct damping coefficient $C$ with relative axial rotor position $\mathrm{a} / \mathrm{b}$ at three different seal clearances with the same operating conditions as in Figure 4. For all the three clearances considered, downstream rotor shifting steadily decreases the magnitude of both cross-coupled stiffness and direct damping. Furthermore, seal rotordynamics is found to be sensitive to axial rotor position. For a given seal clearance $C_{r}=0.254 \mathrm{~mm}$, for example, the cross-coupled stiffness $k$ reduces $39.8 \%$ from $\mathrm{a} / \mathrm{b}=0.0$ to $\mathrm{a} / \mathrm{b}=0.25$, and $42.3 \%$ from $\mathrm{a} / \mathrm{b}=0.25$ to $\mathrm{a} / \mathrm{b}=0.5$. In addition, almost no discernible variation of direct damping was found for the seal clearances considered.

The effective damping $\left(C_{\text {eff }}=C-K / \Omega\right)$, which incorporates the typically destabilizing force coefficient $k$ and the stabilizing force $C$, represents the net tangential force acting on the rotor. Subsynchronous vibration (e.g., $\Omega=0.5 \omega$ ) was assumed in evaluating the net force coefficient $C_{\text {eff. }}$. When positive, the net damping force acts in the direction opposite to the rotor whirl and therefore it represents the net stabilizing force. From Figure 7, it is evident that the seal with an axial rotor position $\mathrm{a} / \mathrm{b}=0.0$ is the most destabilizing. The stability characteristics are improved steadily as the rotor shifts downstream from $\mathrm{a} / \mathrm{b}=0.0$ to $\mathrm{a} / \mathrm{b}=1.0$.

Seal inlet swirl is well recognized as a major effect that contributes to turbomachinery seal instability. A better understanding of the influence of rotor shifting can be acquired by examining the seal rotordynamics variation with inlet swirl $W_{0}$ as well as with various rotor axial shift positions.

Figure 8 shows the variation of $k$ and $C$ with seal inlet swirl velocity $W_{0}$ for a high-low seal with three different ax-

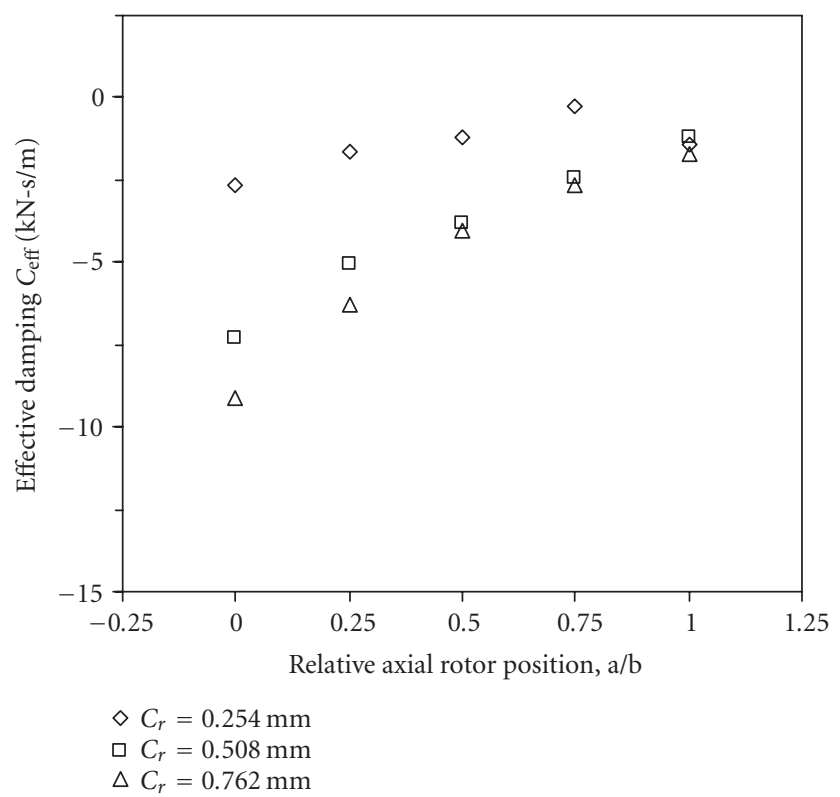

FIGURE 7: Predicted effective damping coefficient versus relative axial rotor position $\mathrm{a} / \mathrm{b}$ for high-low seals.

ial rotor positions as well as a straight-through "ST_TH" seal whose geometry is shown in Figure 3(c). The running speed and other conditions are the same as in Figures 4 through 7. From Figure 8 it is found that both $k$ and $C$ exhibit a nearly 


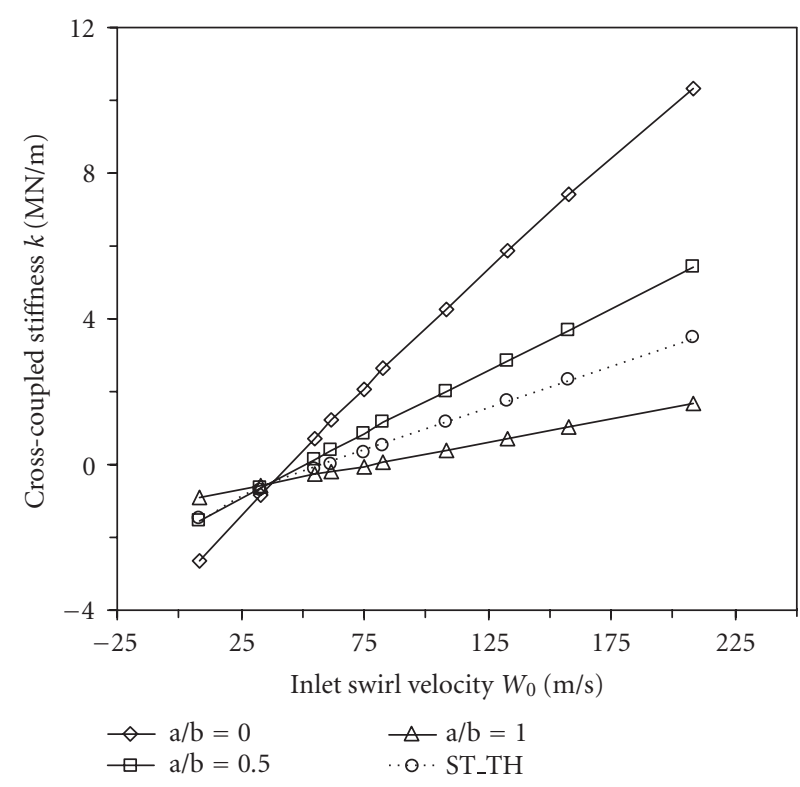

(a)

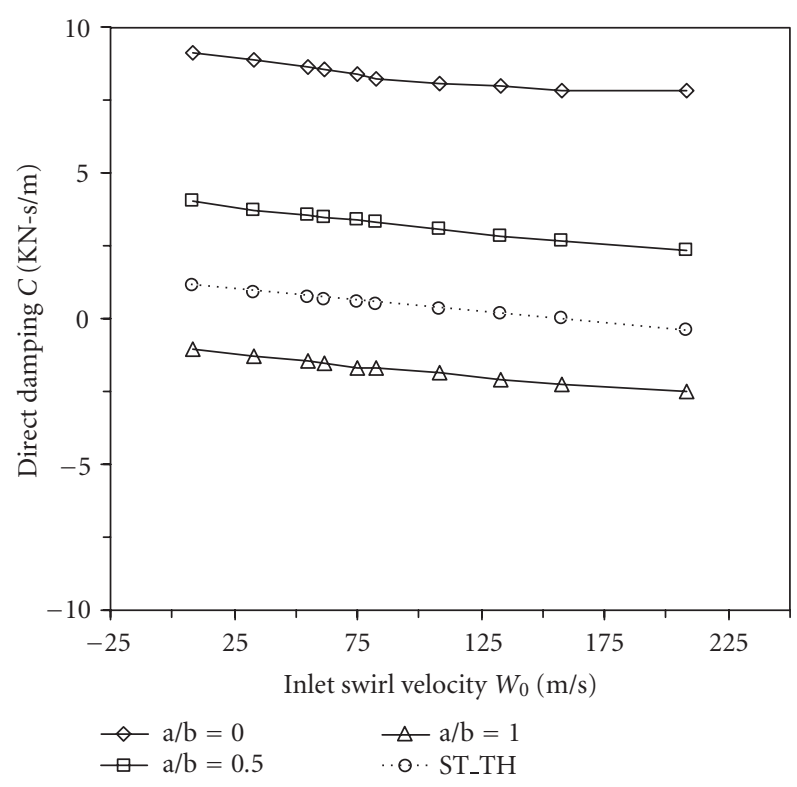

(b)

FIGURE 8: Plot of cross-coupled stiffness $k$ and direct damping $C$ versus inlet swirl velocity $W_{0}$ for different seal configurations: (a) crosscoupled stiffness; (b) direct damping.

linear dependence on $\mathrm{W}_{0}$ for the high-low seal as well as for the straight-through seal. Another important finding from Figure 8 is that both $k$ and $C$ show surprisingly large sensitivities to axial rotor position, especially when $W_{0}$ is large. Further, very similar to data shown by Childs [16] for straightthrough labyrinth, the high-low labyrinth at $\mathrm{a} / \mathrm{b}=0.5$ shows that $k$ exhibits an important sensitivity to seal inlet swirl, whereas the direct damping coefficient has only a slight sensitivity.

It was further found from Figure 8(a) that, for both straight-through and high-low labyrinths with various values of axial shift, the curves of $k$ versus $W_{0}$ all intersect at one particular point. The seal-inlet swirl velocity $W_{0}$ at this intersection point is approximately 60 percent of the rotor peripheral speed, which coincidently is approximately the seal asymptotic swirl velocity (i.e., the seal exit swirl velocity for an extremely long seal). This implies that rotor axial shifting has a negligible effect on $k$ (seal rotordynamic driving force) when the seal inlet swirl is approximately the seal asymptotic swirl (i.e., $W_{0} \approx 0.6 \omega R_{\mathrm{sh}}$ ). Specifically, when the swirl velocity remains fairly constant along the seal length, $k$ is independent of high-low seal axial shifting.

Figure 9 shows that rotor axial shifting has a negligible effect on $C_{\text {eff }}$ (net rotordynamic damping force) when $W_{0} \approx 1.2 \omega R_{\mathrm{sh}}$. Because $C$ is not very sensitive to the seal inlet swirl as shown in Figure 8(b), the $C_{\text {eff }}$ combination of $k$ and $C$ gives a different inlet swirl value for which shiftindependent behavior occurs.

Figure 10 illustrates the variation of direct stiffness $K$ with rotor axial shift seal configuration and inlet swirl ve-

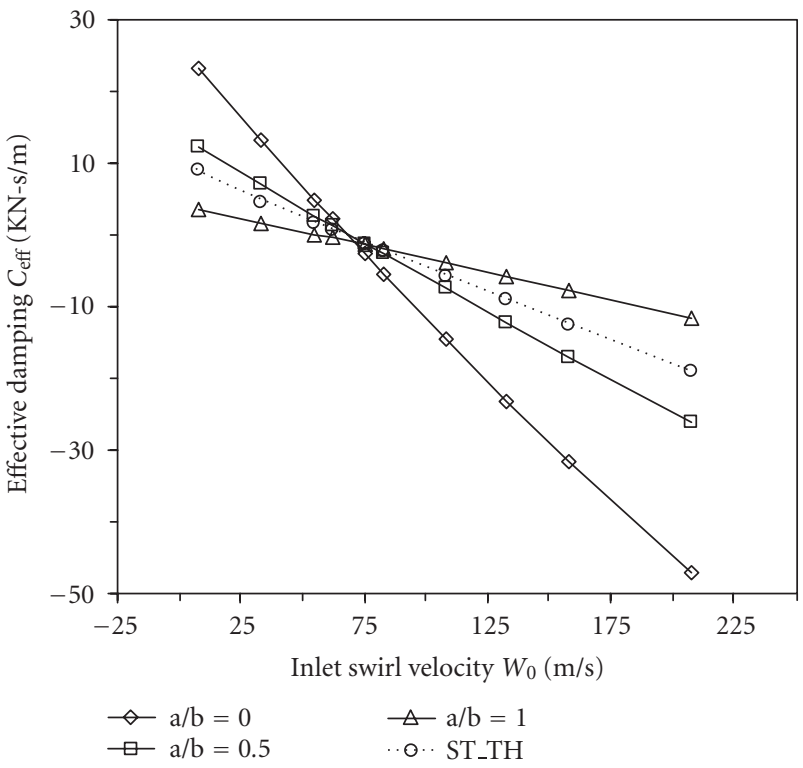

Figure 9: Plot of effective damping $C_{\text {eff }}$ versus inlet swirl velocity $W_{0}$ for different seal configurations.

locity. For all three clearances, $K$ decreases as the rotor shifts downstream from $\mathrm{a} / \mathrm{b}=0.0$ to $\mathrm{a} / \mathrm{b}=1.0$. Additionally, a large sensitivity of $K$ to labyrinth seal configuration is observed from Figure 10(b). It is obvious that the straight-through seal 


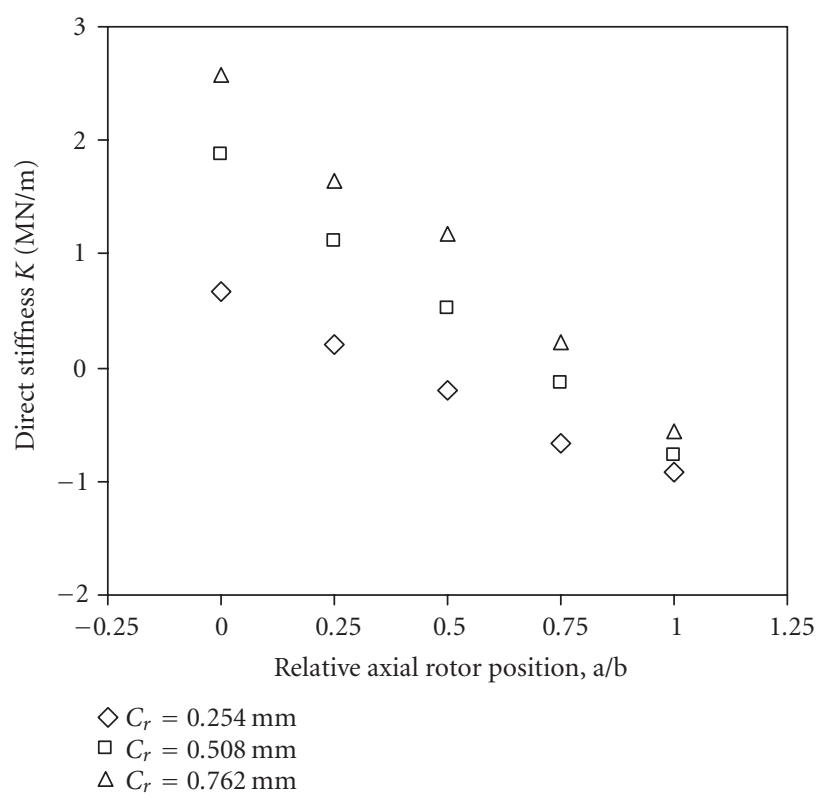

(a) Effect of rotor axial shift

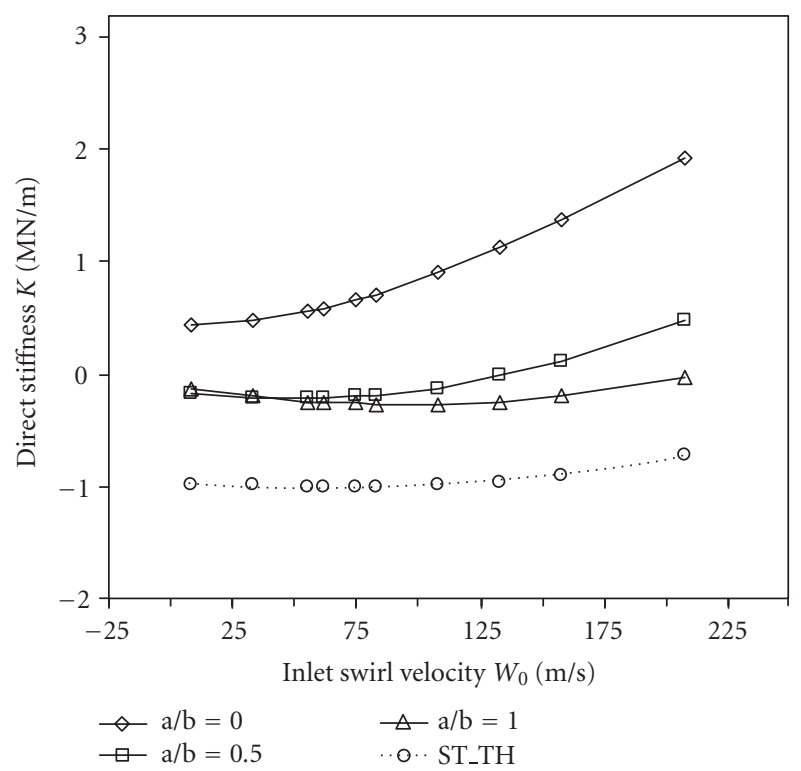

(b) Effect of inlet swirl

FIGURE 10: Predicted direct stiffness K: (a) effect of rotor axial shift; (b) effect of inlet swirl velocity.

gives the lowest $K$ of all the seal configurations considered. Perhaps this can be attributed to the fact that there is no radial impingement of the leakage through-flow jet on the rotor for straight-through seals.

Figure 11 shows the $C_{\text {eff }}$ distribution along the rotor surface for the high-low seal, with the thick line denoting the high portion (i.e., rotor block) and the thin line denoting the low portion (i.e., groove). By comparing the $C_{\text {eff }}$ magnitude at the three axial rotor positions, it can be observed that the first several cavities, especially the first and the second, are more important in determining seal stability than the others. Observe that for these cases where the seal-inlet swirl is greater than the rotor peripheral speed, a large destabilizing effect is produced in the first two labyrinth cavities, which then gradually decreases for the subsequent cavities and even becomes stabilizing for the last cavities. Specifically, the low portion immediately downstream of the first rotor block dominates the rotordynamic stability characteristics of the high-low labyrinth. This is compatible with the recent experimental results of Iwatsubo and Iwasaki [17] who found that adding swirl brakes at the inlet, particularly inside the first and second cavities, was effective in dramatically reducing the net destabilizing force as well as the circumferential swirl velocity.

Interestingly, for the two extreme positions $\mathrm{a} / \mathrm{b}=0.0$ and $\mathrm{a} / \mathrm{b}=1.0$, the rotordynamic influence from the first several cavities is much larger in magnitude than that from the last several cavities. However, for the teeth-centered position $(\mathrm{a} / \mathrm{b}=0.5)$, the rotordynamic influence from the last several cavities is comparable to that from the first several cavities.
It is hypothesized that the near-rotor swirl velocity variation along the leakage direction in the seal has a substantial effect on seal stability characteristics, thereby explaining the apparently large difference in the rotordynamic sensitivities to rotor axial position. Figure 12 shows the axial distribution of near-rotor swirl inside the first and second cavities for the operational conditions of Figures 6 and 7. (The seal clearance is $0.254 \mathrm{~mm}$ and the definition of points D, E, F, G can be found in Figure 3(a).) Recall from Figure 4 that axial shift position $\mathrm{a} / \mathrm{b}=1.0$ typically gives the minimum leakage, and Figure 12 shows that this axial shift position also gives the minimum near-rotor swirl. For a fixed seal inlet swirl velocity, the near-rotor swirl velocity inside the seal is influenced by the leakage rate, or equivalently by the fluid particle residence time within the seal. That is, the smaller the leakage is, the longer the residence time is, and thus the more a fluid particle might change from its seal inlet swirl value toward the asymptotic-swirl value, which is about 60 percent of the rotor peripheral speed. Specifically, it is found that for cases where the seal inlet swirl $W_{0}$ is greater than the asymptotic-swirl, the bulk swirl decreases toward the seal exit, which for the present cases at least produces a net destabilizing force. It was further found that when the leakage was reduced for such $W_{0}>$ asymptotic-swirl cases, the seal-exit swirl was reduced due to the increased residence time, giving a correspondingly reduced destabilizing tangential force. This seal rotordynamics relationship with leakage is endorsed by the effective damping coefficient variation with leakage for a high-low labyrinth seal at a/b $=0.0$ as shown in Figure 13 . Observe that as the leakage decreases for fixed $W_{0}$ the destabilizing force decreases in magnitude. 


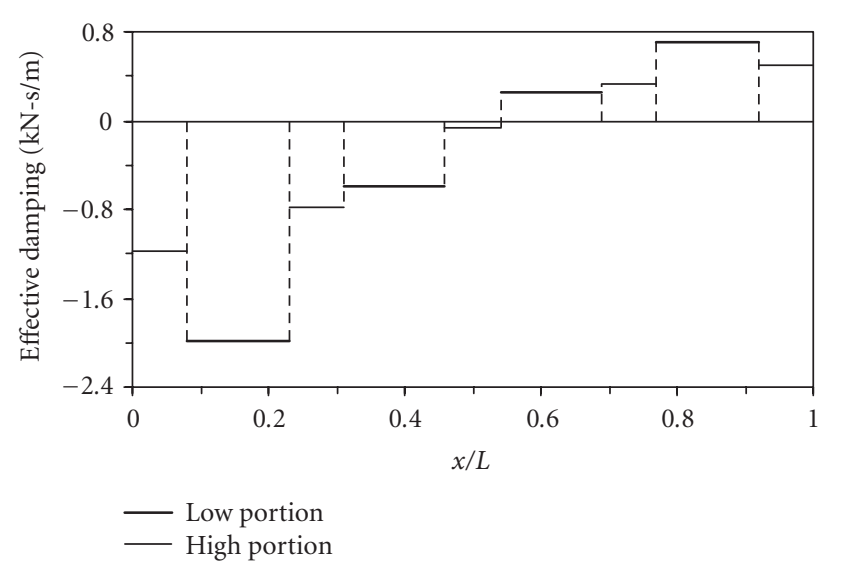

(a)

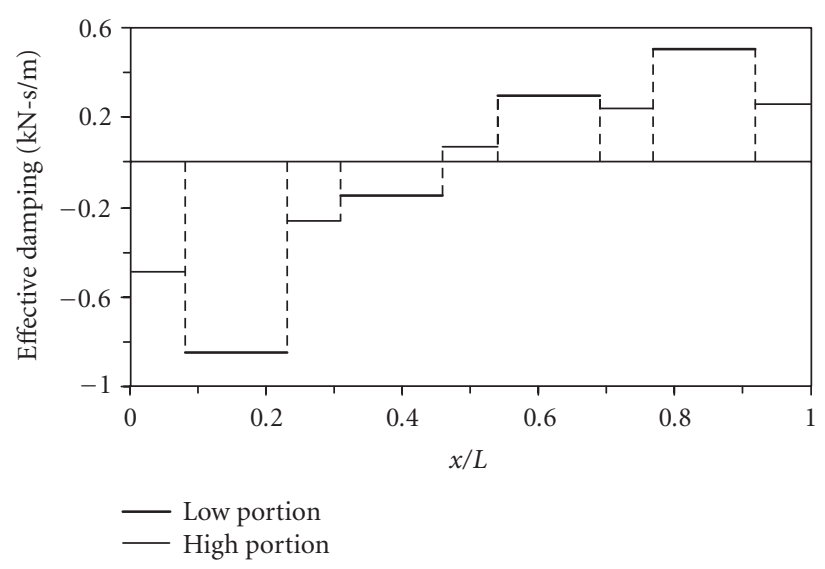

(b)

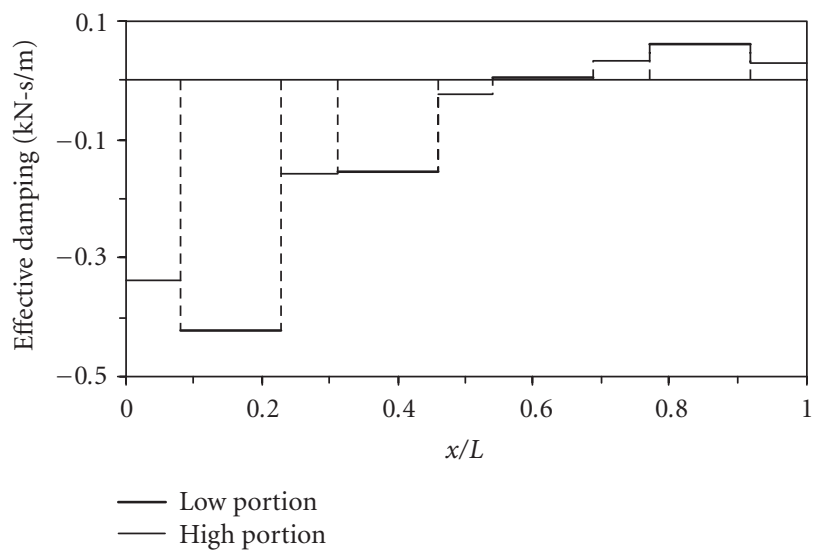

(c)

FIGURE 11: Effective damping distribution along the rotor surface for high-low seals at different relative axial rotor positions: $(\mathrm{a}) \mathrm{a} / \mathrm{b}=0.0$; (b) $\mathrm{a} / \mathrm{b}=0.5 ;$ (c) $\mathrm{a} / \mathrm{b}=1.0$.

\section{SUMMARY}

Numerical studies were performed to investigate the influence of rotor axial shifting on rotordynamic forces in highlow labyrinth seals using a CFD modeling approach. Various operational conditions were considered to gain a better understanding of the labyrinth seal rotordynamics, which covered a range of seal clearances and seal-inlet swirl velocities. Seal configurations were found to have a surprisingly large effect on dynamic force coefficients. A seal rotordynamic relationship with leakage was proposed to explain the variations of the seal stability sensitivity to the rotor axial shifting. Specific findings include the following.

(1) Rotor axial shifting was found to have surprisingly large effects on rotordynamic force coefficients. Both $k$ and $C$ show sensitivities to labyrinth seal configurations due to different relative rotor-teeth positions. The variation of cross-coupled stiffness $k$ between a/b
$=0.5$ and $\mathrm{a} / \mathrm{b}=0.0$, for example, is $143 \%$ for a highlow labyrinth seal with $C_{r}=0.254 \mathrm{~mm}$ and $125 \%$ for a seal with $C_{r}=0.508 \mathrm{~mm}$.

(2) Compared to a seal with a centered teeth position $(a / b=0.5)$, the seal with rotor-shifting in the upstream direction (i.e., against the leakage) suffers an increased leakage and produces a more destabilizing rotordynamic effect, while the seal with downstream rotorshifting gives a reduced leakage and a less destabilizing effect.

(3) Cross-coupled stiffness was found to show negligible dependence on rotor position when the seal inlet swirl approximately equals the seal asymptotic swirl (i.e., $W_{0} \approx 0.6 \omega R_{\mathrm{sh}}$ ), and the swirl velocity remains fairly constant along the seal length.

(4) The first several cavities, especially the first and the second cavities, are the most important in determining the stability characteristics for high-low labyrinth seals. 


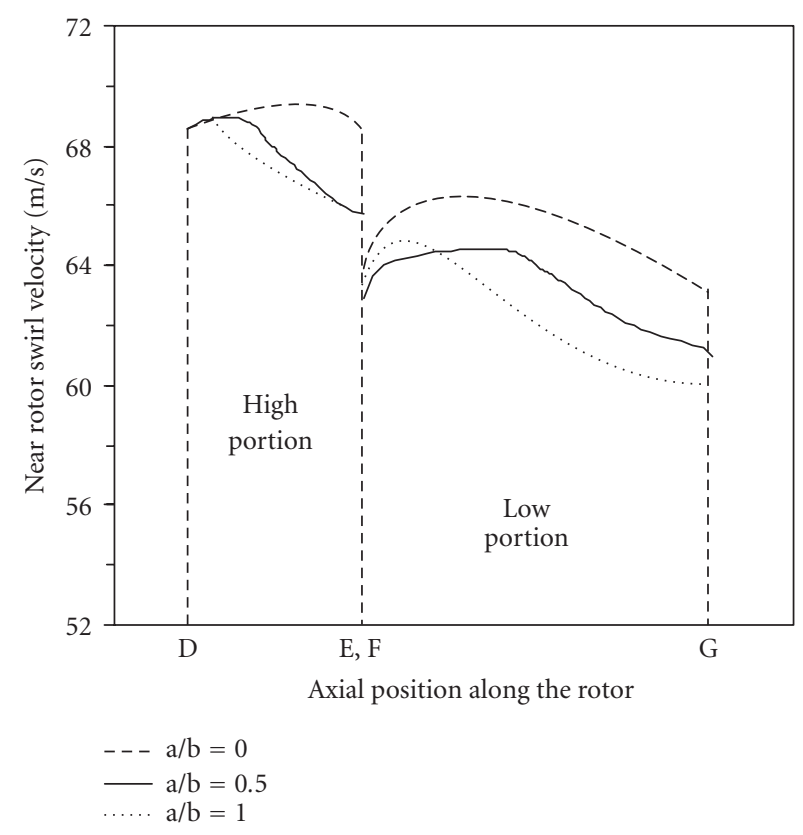

FIgURe 12: Axial distribution of swirl velocity within a high-low labyrinth seal: high portion, D-E; low portion, F-G.

(5) The substantial influence of swirl variation along the rotor on seal rotordynamics is suggested to explain the large sensitivity differences of seal rotordynamics caused by the rotor axial shifting.

\section{Nomenclature}

\begin{tabular}{|c|c|}
\hline$C_{r}$ & Seal radial clearance $(\mathrm{m})$ \\
\hline$C, c$ & $\begin{array}{l}\text { Direct and cross-coupled damping } \\
\text { coefficients }(\mathrm{N}-\mathrm{s} / \mathrm{m})\end{array}$ \\
\hline$e$ & Radius of rotor whirling motion $(\mathrm{m})$ \\
\hline$F$ & Fluid reaction force $(\mathrm{N})$ \\
\hline$K, k$ & $\begin{array}{l}\text { Direct and cross-coupled stiffness } \\
\text { coefficients }(\mathrm{N} / \mathrm{m})\end{array}$ \\
\hline$M, \mathrm{~m}$ & Direct and cross-coupled inertial coefficients $(\mathrm{kg})$ \\
\hline$P$ & Pressure $(\mathrm{Pa})$ \\
\hline$R$ & Universal gas constant $[\mathrm{N}-\mathrm{m} /(\mathrm{kg} \cdot \circ \mathrm{K})]$ \\
\hline$U, V, W$ & Axial, radial, and swirl velocity components, $(\mathrm{m} / \mathrm{s})$ \\
\hline$y$ & Radial distance from rotor surface $(\mathrm{m})$ \\
\hline
\end{tabular}

\section{Greek symbols}

$\epsilon \quad$ Relative eccentricity of the rotor $\left[e / C_{r}\right]$

$\Phi$ General dependent variable

$\kappa \quad$ Turbulence kinetic energy $\left[\mathrm{m}^{2} / \mathrm{s}^{2}\right]$

$\mu \quad$ Dynamic viscosity $[\mathrm{g} /(\mathrm{ms})]$

$\theta$ Circumferential coordinate

$\rho \operatorname{Density}\left(\mathrm{kg} / \mathrm{m}^{3}\right)$

$\omega \quad$ Shaft speed (rpm)

$\Omega \quad$ Rotor whirling speed (rpm)

$\gamma \quad$ The gas compressibility factor

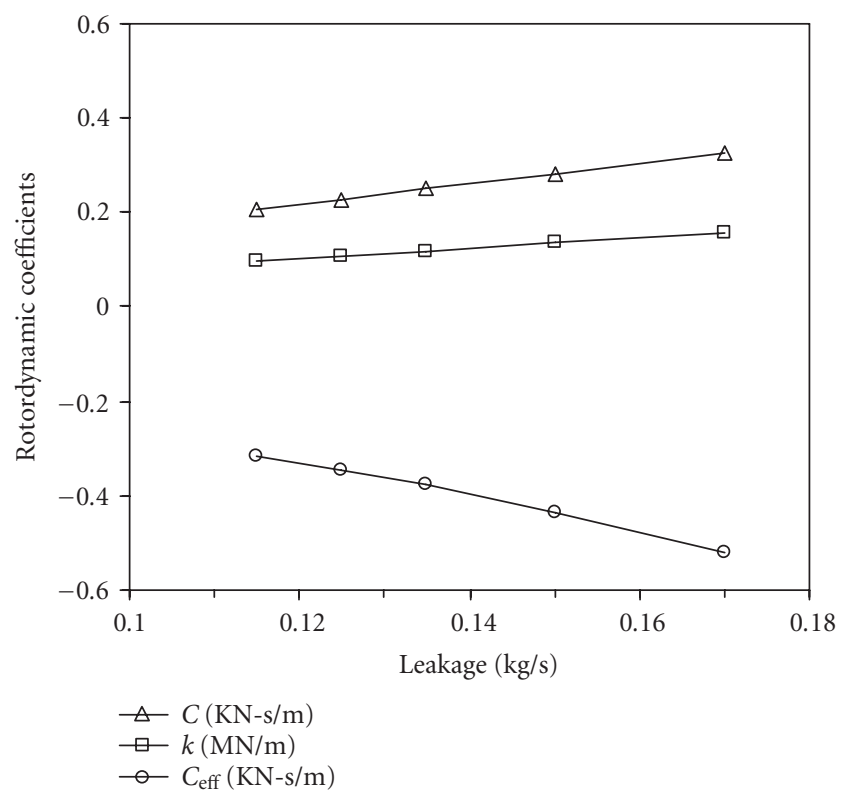

FIGURE 13: Variation of rotordynamic coefficients with seal leakage (seal inlet swirl $=70 \mathrm{~m} / \mathrm{s}$; asymptotic swirl $\approx 0.6\left(\omega R_{\mathrm{sh}}\right)=31.2 \mathrm{~m} / \mathrm{s}$; $\mathrm{a} / \mathrm{b}=1.0)$.

\section{Subscripts}

dn Downstream

$r$ Radical direction

sh Shaft

up Upstream

0,1 Zeroth- and first-order, respectively

$1 c$ First-order cosine component

1s First-order sine component

\section{ACKNOWLEDGMENTS}

The authors appreciate the financial support from the Texas ATP, and the Supercomputer Center of Texas A\&M University.

\section{REFERENCES}

[1] T. Iwatsubo, "Flow induced force and flow patterns of labyrinth seals," in NASA Conference Publication, no. 2250, pp. 205-222, 1982.

[2] J. K. Scharrer, "Theory versus experiment for the rotordynamic coefficients of labyrinth gas seals. Part I: a two control volume model," Journal of Vibration, Acoustics, Stress, and Reliability in Design, vol. 110, no. 3, pp. 270-280, 1988.

[3] D. W. Childs and J. K. Scharrer, "Theory versus experiment for the rotordynamic coefficients of labyrinth gas seals. Part II: a comparison to experiment," Journal of Vibration, Acoustics, Stress, and Reliability in Design, vol. 110, no. 3, pp. 281-287, 1988.

[4] E. A. Soto and D. W. Childs, "Experimental rotordynamic coefficient results for (a) a labyrinth seal with and without shunt injection and (b) a honeycomb seal," Journal of Engineering for Gas Turbines and Power, vol. 121, no. 1, pp. 153-159, 1999. 
[5] K. Kwanka and M. Nagel, "Experimental rotordynamic coefficients of short labyrinth gas seals," in NASA Conference Publication, Rotordynamic Instability Problems in High-Performance Turbomachinery, no. 3344, pp. 135-144, 1996.

[6] H. F. Black and D. N. Jensen, "Dynamic hybrid properties of annular pressure seals," Journal of Mechanical Engineers, vol. 113, pp. 353-361, 1970.

[7] D. W. Childs, "Dynamic analysis of turbulent annular seals based on Hirs' lubrication equation," ASME Journal of lubrication technology, vol. 105, no. 3, pp. 429-436, 1983.

[8] F. J. Dietzen and R. Nordmann, "Calculating rotordynamic coefficients of the seals by finite-difference techniques," ASME Journal of Tribology, vol. 109, pp. 338-394, 1987.

[9] N. Kim and D. L. Rhode, "A new CFD-perturbation model for the rotordynamic of incompressible flow seals," in Proceedings of ASME TURBO EXPO 2000, Munich, Germany, May 2000, 2000-GT-402.

[10] J. Xi and D. L. Rhode, "Seal-inlet disturbance boundary condition correlations for rotordynamic models, part 1: correlation development," to appear in Tribology Transactions.

[11] J. Xi and D. L. Rhode, "Seal-inlet disturbance boundary condition correlations for rotordynamic models, part 2: assessment," to appear in Tribology Transactions.

[12] U. Baumann, "Rotordynamic stabilty tests on high-pressure radial compressors," in Proceedings of 28th Turbomachinery Symposium, pp. 115-122, Turbomachinery Laboratory, Texas A\&M University, College Station, Tex, USA, 1999.

[13] Y. Wang, C. Young, G. Snowsill, and T. Scanlon, "Study of airflow features through step seals in the presence of Disengagement due to axial movement," in Proceedings of the ASME Turbo Expo 2004, vol. 4, pp. 241-248, Vienna, Austria, June 2004, GT2004-53056.

[14] B. E. Launder and D. B. Spalding, "The numerical computation of turbulent flows," Computer Methods in Applied Mechanics and Engineering, vol. 3, no. 2, pp. 269-289, 1974.

[15] N. Kim, S.-Y. Park, and D. L. Rhode, "Predicted effects of shunt injection on the rotordynamics of gas labyrinth seals," ASME Journal of Engineering for Gas Turbines and Power, vol. 125, no. 1, pp. 167-174, 2003.

[16] D. W. Childs, Turbomachinery Rotordynamics, John Wiley \& Sons, New York, NY, USA, 1993.

[17] T. Iwatsubo and Y. Iwasaki, "Experimental and theoretical study on Swirl_Braked labyrinth seal," in Proceedings of the 6th International Conference on Rotor Dynamics (IFToMM '02), pp. 564-572, Sydney, Australia, September-October 2002. 

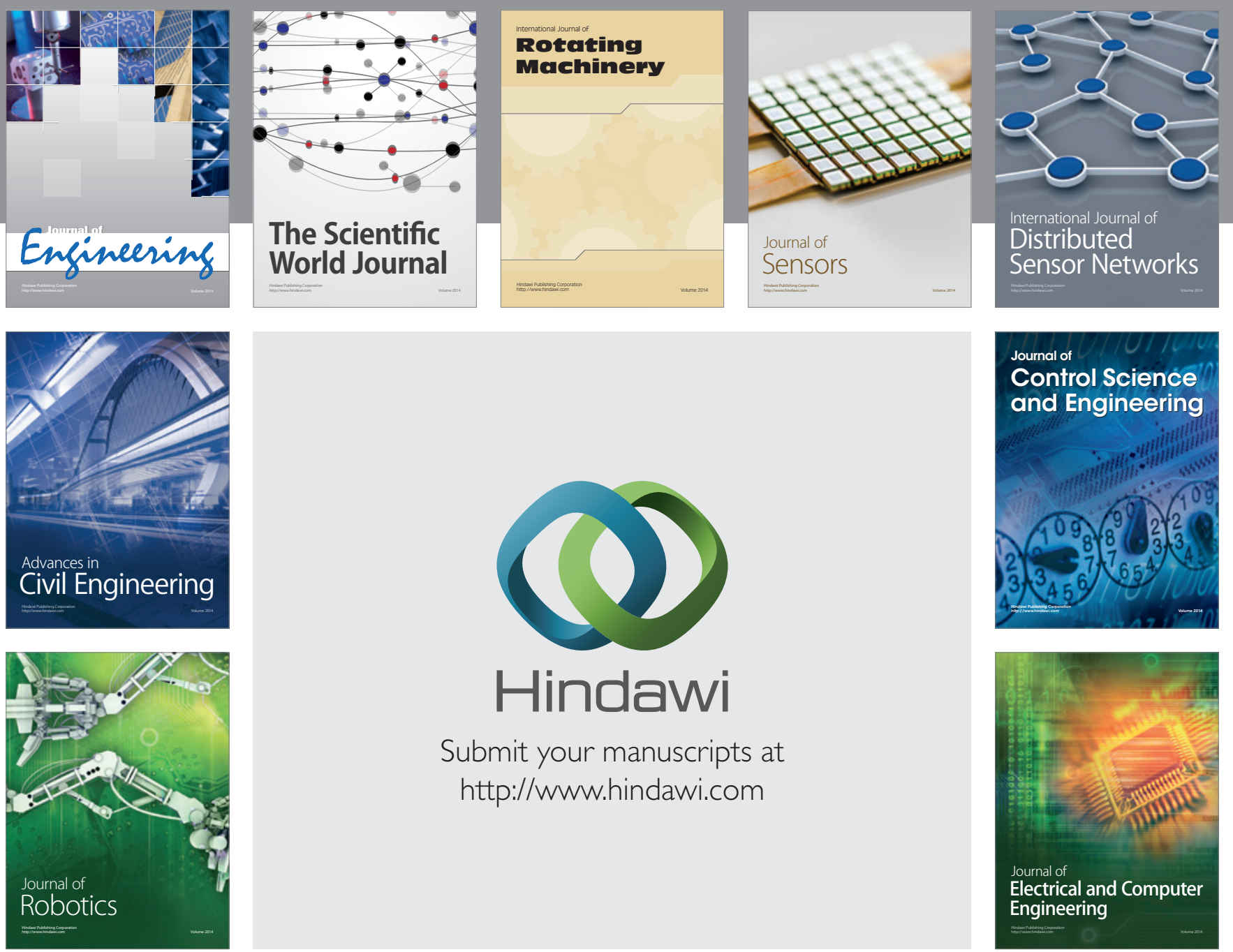

Submit your manuscripts at

http://www.hindawi.com
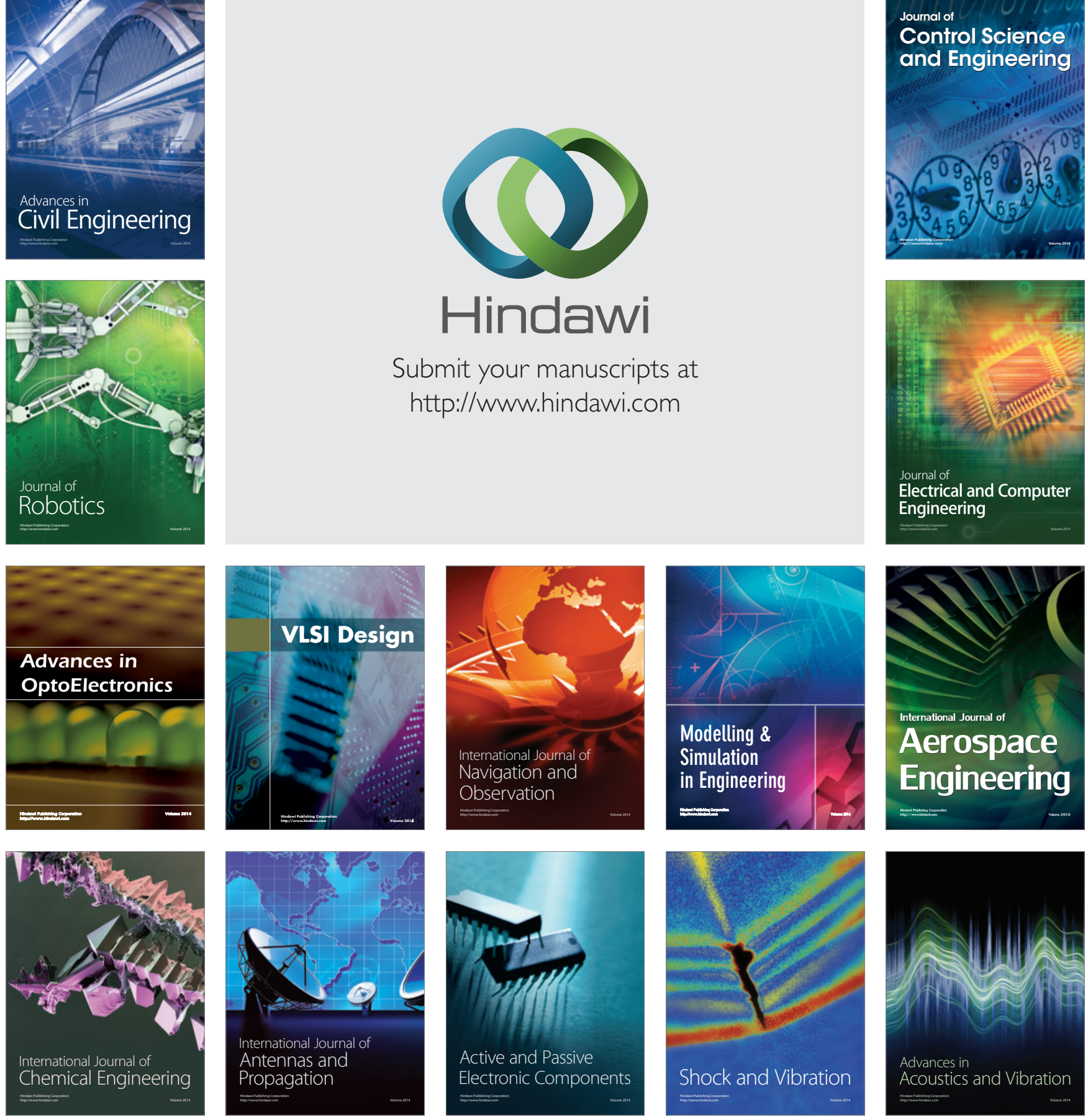